\title{
Estimation of $\mathrm{NO}_{\mathrm{x}}$ deposition velocities for selected commercial photocatalytic products
}

\author{
M. Palacios ${ }^{1}$, L. Núñez ${ }^{1}$, M. Pujadas ${ }^{1}$, J. Fernández-Pampillón ${ }^{2}$, \\ M. Germán ${ }^{1}$, B. S. Sánchez ${ }^{1,3}$, J. L. Santiago ${ }^{1}$, A. Martillii ${ }^{1}$, \\ S. Suárez ${ }^{1} \&$ B. S. Cabrero ${ }^{1}$ \\ ${ }^{I}$ Centro de Investigaciones Energéticas, Medioambientales y \\ Tecnológicas (CIEMAT), Spain \\ ${ }^{2}$ Universidad Nacional de Educación a Distancia (UNED), Spain \\ ${ }^{3}$ Ingeniería y Economía del Transporte (INECO), Spain
}

\begin{abstract}
The photocatalytic degradation of nitrogen oxides $\left(\mathrm{NO}_{\mathrm{x}}\right)$ employing a wide variety of different materials with titanium dioxide is studied experimentally following diverse approaches; both laboratory tests as ambient air experiments. Then, different approximations are applied to estimate $\mathrm{NO}_{\mathrm{x}}$ deposition velocities by using the experimental data obtained for the most efficient photocatalytic materials under study. Estimates for NO are of the same order of magnitude but could differ significantly depending on the test or experiment and the numerical method followed for their calculation. Estimates for $\mathrm{NO}_{2}$ could be only inferred from ambient air measurements, giving values of one order the magnitude lower than those for NO.

Keywords: heterogeneous photocatalysis, photocatalytic materials, $N O_{x}$ deposition velocities, $N O_{x}$ pollution, titanium dioxide.
\end{abstract}

\section{Introduction}

Air pollution caused by road traffic is one of the major problems in metropolitan and urban areas. In particular, despite the increased control requirements and the installation of emission reduction systems, air pollution by nitrogen oxides $\left(\mathrm{NO}_{\mathrm{x}}\right)$ from diesel engines remains a serious concern in inner-city areas [1]. Current environmental legislations [2] establish increasingly limiting values for $\mathrm{NO}_{2}$ that 
promote the research and development and tuning of control strategies that could help to alleviate the atmospheric impact of emission sources.

Applying $\mathrm{TiO}_{2}$-modified coatings or cementitious materials onto the external covering of buildings or roads might be a supplement to conventional technologies, such as catalytic converters fitted on the vehicles, for mitigating air pollution. Nevertheless, although some photocatalytic materials have been deeply studied in laboratory, their efficiency as sink of $\mathrm{NO}_{\mathrm{x}}$ at real scale is still a matter of debate.

In the framework of the LIFE MINO $_{\mathrm{x}}$-STREET European project, co-financed by the EU, devoted to clarify some of the remaining technical doubts, a variety of commercial photocatalytic building and construction materials and coatings has been subjected to rigorous laboratory essays and then, some of these products selected in order to evaluate their depolluting effect at real scale.

In order to assess which could be the environmental effect on pollution levels if photocatalytic materials were applied in one street of a particular city or, furthermore, modelling the foreseen effects if such materials were implemented in the whole city, $\mathrm{NO}_{\mathrm{x}}$ deposition velocities need to be estimated.

In this work, the air purifying ability of a variety of commercial products is quantified under different experimental conditions, by using both laboratory tests and an experimental system designed for measuring $\mathrm{NO}_{\mathrm{x}}$ deposition flows over photocatalytic surfaces in ambient air, and several numerical approaches for estimating $\mathrm{NO}_{\mathrm{x}}$ deposition velocities are described and the estimates compared.

\section{Selection of photocatalytic materials}

Assessing the role that the use of commercial photocatalytic materials designed to air purification could play in combination with other strategies for air quality management make imperative to provide evidences from rigorous essays and tests on their physical-chemical properties and expected efficiency, not only under controlled laboratory conditions but also in real atmosphere.

Since the variety of different commercial photoactive materials offered by the European market is very wide, a rigorous selection of the materials and conditions of use is needed.

The work presented here forms part of the strict essay protocol developed in the framework of the European project LIFE MINO ${ }_{x}$-STREET to test and compare the potential usefulness of a variety of commercial photocatalytic materials to act as $\mathrm{NO}_{\mathrm{x}}$ sink when are implemented on urban surfaces at real conditions.

On the one hand, their mechanical and physical properties, operation-induced changes and durability, involving both laboratory essays and large scale experiments, have been tested. On the other hand, their photoactivation and airpurifying capacity, chemical and structural properties and changes induced by ageing and regeneration processes, both under controlled as ambient conditions, have been investigated and documented. Finally, the selection, among them, of 
the most promising photoactive materials to be applied and tested at large scale under real ambient conditions has been done.

In the following sections, we present the essays and experiments carried out in order to characterize the air-purifying ability of several selected materials and estimate $\mathrm{NO}_{\mathrm{x}}$ deposition velocities that are needed for modellers to evaluate the potential impact of their use at real urban scale.

\section{Photocatalytic activity of selected materials in a bed flow photo-reactor}

After a market study of photocatalytic products available for use in urban settings, several of these products, considered as potentially useful for their application in urban settings, were selected for testing their photocatalytic activity under ISO 22197-1:2007 [3].

In bed flow photo-reactor experiments, like the one presented here, a test gas mixture flow (NO, air, $\left.\mathrm{H}_{2} \mathrm{O}\right)(50 \%$ relative humidity) is passed over the flat rectangular sample of typically $5 \mathrm{~cm} \times 10 \mathrm{~cm}$ and is irradiated by UV-A light ( $10 \mathrm{~W} \mathrm{~m}^{-2}$ irradiance) through a UV transparent window with a distance to the sample of $5 \mathrm{~mm}$. Under the conditions applied, a laminar-plugged flow is assumed and very short reaction times of only a few seconds are obtained. This set-up is comparable to a classical flow tube approach often used in heterogeneous chemistry [4]. However, in contrast to a classical first-order kinetic analysis of the uptake data, only the numbers of $\mathrm{NO}_{\mathrm{x}}$ molecules ( $\left.\mu \mathrm{mol}\right)$ are quantified for a defined concentration, gas flow rate, reaction time and geometry of the reactor are used then for the ranking of the activity of the material.

It has been demonstrated that oxides such as $\mathrm{NO}, \mathrm{NO}_{2}$ at low concentration levels can be treated by $\mathrm{TiO}_{2}$ under UV irradiation [5]. The mechanism of pollution decomposition is described elsewhere [6].

The amount of $N O$ removed from the test gas can be calculated following the formula given by the ISO 22197-1:2007:

$$
n_{N O}=(f / 22,4) \int\left(\emptyset_{N O_{i n}}-\emptyset_{N O_{o u t}}\right) d t
$$

where $n_{N O}$ is the amount of $N O$ removed by the test piece $(\mu \mathrm{mol}), f$ is the airflow rate converted into that at the standard state $\left(0^{\circ} \mathrm{C}, 101.3 \mathrm{kPa}\right.$, and dry gas basis) $\left(1 \mathrm{~min}^{-1}\right), \emptyset_{N O_{i n}}$ is the supply volume fraction of nitric oxide $\left(\mu \mathrm{l}^{-1}\right)$ and $\emptyset_{N O_{\text {out }}}$ is the nitric oxide volume fraction at the reactor exit $\left(\mu \mathrm{l} \mathrm{l}^{-1}\right)$.

Another way to express the photocatalytic efficiency is the conversion $\chi$. This is a dimensionless measure of the NO abatement and it is a function of the initial and final concentrations of the pollutant. The conversion is defined as:

$$
\chi=\left(\frac{\emptyset_{N o_{i n}}-\emptyset_{N O_{o u t}}}{\emptyset_{N O_{\text {in }}}}\right) \cdot 100
$$


The photocatalytic efficiency of a wide variety of materials suitable for application on three types of surfaces has been tested: bituminous pavement, concrete pavements (sidewalks) and facades (see Table 1). The results were very different and are presented in Tables 2 to 4 . Only significantly active materials are included here. A detailed discussion of the factors influencing the photocatalytic efficiency observed is out of the scope of this work. However, it is important to note that not only the substrate and photocatalytic products but also the way of application of those products (spraying, rolling) can have a huge influence in the efficiency observed. So, apart from the inter-sample variability that can be expected, the intra-sample variability can be non-negligible in some cases and should be taken into account and quantified. This factor could have a greater relevance at real scale where the conditions of application are not always so well controlled.

Table 1: Nomenclature used to show the results of efficiency $\left(\chi\right.$ and $\left.n_{N O}\right)$ for tested photocatalytic materials.

\begin{tabular}{|ll|}
\hline Nomenclature & \\
CP: Concrete pavement & \\
& \\
PPB & photocatalytic paving block \\
PPS & photocatalytic paving slab \\
PB & paving block \\
PS & paving slab \\
SG & photocatalytic sol-gel \\
WE & photocatalytic water emulsion \\
PC & photocatalytic coating \\
Xcp $1-\mathrm{Xcp}_{5}$ & different manufacturers of photocatalytic products \\
& \\
BP: bituminous pavement & \\
& \\
OP & open graded \\
CG & close graded \\
EBM & elastomeric bitumen membrane \\
M & photocatalytic mortar \\
WE & photocatalytic water emulsion \\
Xbp $1-\mathrm{Xbp}_{3}$ & different manufacturers of photocatalytic products \\
& \\
F: Facade & \\
& \\
CS & \\
CL & concrete surface \\
FB & concretal lasur \\
EBM & face brick \\
PP & elastomeric bitumen membrane \\
PC & photocatalytic paint \\
MP & photocatalytic coating \\
BP & monocomponent paint \\
Xf $f_{1}-\mathrm{Xf}_{6}$ & bicomponent paint \\
& different manufacturers of photocatalytic products \\
\hline
\end{tabular}


Table 2: $\quad$ Photocatalytic efficiency $\left(\chi\right.$ and $\left.n_{N O}\right)$ and standard deviation for tested photocatalytic products on diverse concrete pavements.

\begin{tabular}{|c|c|c|c|c|c|c|}
\hline Substrate & $\begin{array}{c}\text { Types of } \\
\text { substrate }\end{array}$ & Product & Manufacturers & $\begin{array}{c}\text { Types of } \\
\text { sample }\end{array}$ & $\begin{array}{c}\chi \\
(\%)\end{array}$ & $\begin{array}{c}n_{N o} \\
(\mu \mathrm{mol})\end{array}$ \\
\hline $\mathrm{CP}$ & 4 & $\mathrm{PPB}$ & $\mathrm{Xcp}_{1}-\mathrm{Xcp}_{3}$ & 4 & $8.3 \pm 2.6$ & $3.5 \pm 1.1$ \\
\hline $\mathrm{CP}$ & 2 & $\mathrm{PPS}$ & $\mathrm{Xcp}_{1}-\mathrm{Xcp}_{2}$ & 2 & $5.5 \pm 3.5$ & $2.3 \pm 1.6$ \\
\hline $\mathrm{CP}(\mathrm{PS})$ & 1 & $\mathrm{SG}$ & $\mathrm{Xcp}_{3}$ & 1 & 10.0 & 4.2 \\
\hline $\mathrm{CP}(\mathrm{PS})$ & 6 & $\mathrm{WE}$ & $\mathrm{Xcp}_{4}$ & 6 & $34.2 \pm 7.2$ & $12.9 \pm 2.6$ \\
\hline $\mathrm{CP}(\mathrm{PB})$ & 1 & $\mathrm{WE}$ & $\mathrm{Xcp}_{4}$ & 1 & 43.0 & 16.6 \\
\hline $\mathrm{CP}(\mathrm{PS})$ & 2 & $\mathrm{PC}$ & $\mathrm{Xcp}_{5}$ & 2 & $53.0 \pm 17.0$ & $19.5 \pm 6.2$ \\
\hline
\end{tabular}

Table 3: Photocatalytic efficiency $\left(\chi\right.$ and $\left.n_{N O}\right)$ and standard deviation for tested photocatalytic products on diverse bituminous pavements.

\begin{tabular}{|c|c|c|c|c|c|c|}
\hline Substrate & $\begin{array}{c}\text { Types of } \\
\text { substrate }\end{array}$ & Product & Manufacturers & $\begin{array}{c}\text { Types of } \\
\text { sample }\end{array}$ & $\begin{array}{c}\chi \\
(\%)\end{array}$ & $\begin{array}{c}n_{N O} \\
(\mu \mathrm{mol})\end{array}$ \\
\hline $\mathrm{BP}(\mathrm{OG})$ & 3 & $\mathrm{M}$ & $\mathrm{Xbp}_{1}, \mathrm{Xbp}_{2}$ & 4 & $17.0 \pm 8.9$ & $6.3 \pm 3.3$ \\
\hline $\mathrm{BP}(\mathrm{OG})$ & 3 & $\mathrm{WE}$ & $\mathrm{Xbp}_{2}, \mathrm{Xbp}_{3}$ & 4 & $11.8 \pm 10.05$ & $4.2 \pm 3.7$ \\
\hline $\mathrm{BP}(\mathrm{CG})$ & 5 & $\mathrm{WE}$ & $\mathrm{Xbp}_{1}, \mathrm{Xbp}_{3}$ & 6 & $32.2 \pm 7.7$ & $12.1 \pm 2.5$ \\
\hline $\mathrm{EBM}$ & 1 & $\mathrm{WE}$ & $\mathrm{Xbp}_{3}$ & 1 & 43.0 & 17.1 \\
\hline $\mathrm{EBM}$ & 1 & $\mathrm{M}$ & $\mathrm{Xbp}_{1}$ & 1 & 20.0 & 7.4 \\
\hline
\end{tabular}

Table 4: Photocatalytic efficiency $\left(\chi\right.$ and $\left.n_{N O}\right)$ and standard deviation for tested photocatalytic products on diverse façade substrates.

\begin{tabular}{|c|c|c|c|c|c|c|}
\hline Substrate & $\begin{array}{c}\text { Types of } \\
\text { substrate }\end{array}$ & Product & Manufacturers & $\begin{array}{c}\text { Types of } \\
\text { sample }\end{array}$ & $\begin{array}{c}\chi \\
(\%)\end{array}$ & $\begin{array}{c}n_{N O} \\
(\mu \mathrm{mol})\end{array}$ \\
\hline $\mathrm{F}(\mathrm{CS})$ & 1 & $\mathrm{CL}$ & $\mathrm{Xf}_{1}$ & 1 & 24.0 & 8.8 \\
\hline $\mathrm{F}(\mathrm{CS})$ & 1 & $\mathrm{MP}$ & $\mathrm{Xf}_{2}$ & 1 & 37.0 & 13.6 \\
\hline $\mathrm{F}(\mathrm{FB})$ & 2 & $\mathrm{MP}$ & $\mathrm{Xf}_{2}$ & 2 & $27.0 \pm 12.7$ & $10.5 \pm 5.1$ \\
\hline $\mathrm{F}(\mathrm{FB})$ & 1 & $\mathrm{BP}$ & $\mathrm{Xf}_{2}$ & 3 & $13.3 \pm 11.4$ & $5.3 \pm 4.6$ \\
\hline $\mathrm{F}(\mathrm{FB})$ & 1 & $\mathrm{PC}$ & $\mathrm{Xf}_{3}-\mathrm{Xf}_{5}$ & 6 & $13.6 \pm 4.4$ & $5.0 \pm 1.5$ \\
\hline $\mathrm{EBM}$ & 1 & $\mathrm{MP}$ & $\mathrm{Xf}_{2}$ & 1 & 20.0 & 7.4 \\
\hline $\mathrm{EBM}$ & 1 & $\mathrm{PC}$ & $\mathrm{Xf}_{3}$ & 1 & 38.0 & 14.4 \\
\hline
\end{tabular}

\section{Estimation of NO deposition velocities from laboratory test data}

Taking the removed NO as starting point, it is possible to estimate an NO deposition velocity by using the NO mass removed. A surface deposition velocity, $V_{\text {surf }}$, can be approximated from the removed NO under the testing conditions as follows:

$$
F_{\text {surf }}=\frac{f \cdot\left(\emptyset_{N O_{\text {in }}}-\emptyset_{N O_{\text {out }}}\right) / 22,4}{W \cdot L} \cdot M_{N O}
$$

where $W$ is the test piece width (m), $L$ is the test piece length (m), $M_{N O}$ is the molar mass of $\mathrm{NO}\left(\mathrm{g} \mathrm{mol}^{-1}\right)$ and $F_{\text {surf }}$ is the NO flow at the surface (e.g. $\mu \mathrm{g} \mathrm{m}^{-2} \mathrm{~s}^{-1}$ ). 
Then, a surface deposition velocity can be estimated as follows:

$$
V_{\text {surf }}=-\frac{F_{\text {surf }}}{C_{N O_{\text {in }}}}
$$

where $V_{\text {surf }}$ is the deposition velocity $\left(\mathrm{ms}^{-1}\right)$ and $C_{N O_{i n}}$ is the NO mass concentration $\left(\mu \mathrm{g} \mathrm{m}^{-3}\right)$ at the inlet.

On the other hand, in spite of the NO inlet concentration used by this ISO method $\left(1.0 \mu \mathrm{l} \mathrm{l}^{-1} \pm 0.05 \mu \mathrm{l}^{-1}\right)\left(25^{\circ} \mathrm{C}, 1 \mathrm{~atm}\right)$, a classical first-order kinetic analysis of the uptake data has been also used to have another estimation of the deposition velocity as describe below. No deposition velocities for $\mathrm{NO}_{2}$ can be derived from the ISO 22197-1:2007 method since, in fact, $\mathrm{NO}_{2}$, an intermediate of the photocatalytic reaction, is generated from the oxidation of $\mathrm{NO}$ in the system due to the presence of $\mathrm{HO}_{2}^{\circ}$ radicals formed superoxide $\mathrm{O}_{2}^{-}$, especially when the NO inlet concentration is high, as occurs in the present operating conditions $[7,8]$.

At atmospherically relevant low-medium atmospheric pollutant concentrations (e.g. $<100 \mathrm{ppb} \mathrm{NO}_{\mathrm{x}}$ ), the photocatalytic decomposition typically follows first-order kinetics. Under this assumption [9], a first-order rate coefficient $\left(k_{r}\right)$ might be computed from the experimental data:

$$
k_{r}=-\frac{\ln \left(C_{o u t} / C_{i n}\right)}{t_{r}}
$$

where $C_{\text {in }}$ and $C_{\text {out }}$ are the gas mass concentration at the inlet and the outlet of the photo-reactor, and $t_{r}$ is the reaction time of the gas-phase reactant in the sample.

While independent of most variables, $k_{r}$ is still dependent on the geometry of the reactor. To get over this constraint, the dimensionless reactive uptake coefficient $(\gamma)$ has been introduced in heterogeneous chemistry (4) and can be calculated as follows:

$$
\gamma=\frac{4 \cdot k_{r}}{\vartheta \cdot A / V}
$$

where $V$ is the gas-phase volume over the sample $\left(\mathrm{m}^{3}\right)$ and $A$ the area of the photocatalytic sample $\left(\mathrm{m}^{2}\right)$ and $\vartheta$ is the mean molecular velocity of the gas defined by the kinetic gas theory $\left(\mathrm{m} \mathrm{s}^{-1}\right)$. Ordinarily, modellers prefer deposition velocities $\left(v_{\text {surf }}\right)\left(\mathrm{m} \mathrm{s}^{-1}\right)$ in order to compute deposition flux densities of pollutants on surfaces $\left(\mathrm{mol} \mathrm{m} \mathrm{m}^{-2} \mathrm{~s}^{-1}\right)$. Thus, to use laboratory data on resistance patterns, in turn implemented in pollutant dispersion models, an analogue surface deposition velocity can be estimated:

$$
v_{\text {surf }}=\frac{\gamma \cdot \vartheta}{4}
$$

Then, this surface deposition velocity can be used by modellers to calculate the overall deposition velocity, considering also diffusion and convective transport limitations. 
Both approaches, given by eqns (4) and (7), have been used to derive NO deposition rates for photocatalytic materials tested. The obtained estimates for some of the most efficient photocatalytic materials among all tested are shown in Table 5.

Table 5: Deposition velocities for NO from ISO essays data, $V_{\text {surf }}$ and $v_{\text {surf }}$.

\begin{tabular}{|c|c|c|c|c|}
\hline Essay & Substrate category & Product & $\begin{array}{c}V_{\text {surf }} \\
\left(10^{-3} \mathrm{~m} \mathrm{~s}^{-1}\right)\end{array}$ & $\begin{array}{c}v_{\text {surf }} \\
\left(10^{-3} \mathrm{~m} \mathrm{~s}^{-1}\right)\end{array}$ \\
\hline $\mathrm{E} 4_{\mathrm{b} 4}$ & CP (PB) & WE & 4.58 & 6.01 \\
\hline $\mathrm{E} 5_{\mathrm{s} 5 \mathrm{~A}}$ & $\mathrm{CP}(\mathrm{PS})$ & PC & 6.60 & 9.39 \\
\hline $\mathrm{E} 1_{\mathrm{cg} 2}$ & $\mathrm{BP}(\mathrm{CG})$ & WE & 4.64 & 6.10 \\
\hline $\mathrm{E} 3_{\mathrm{ebm}}$ & $\mathrm{EBM}$ & WE & 4.72 & 6.24 \\
\hline $\mathrm{E} 2_{\mathrm{fb} 1 \mathrm{~A}}$ & $\mathrm{~F}(\mathrm{FB})$ & MP & 3.89 & 4.85 \\
\hline $\mathrm{E} 2_{\mathrm{cs}}$ & $\mathrm{F}(\mathrm{CS})$ & MP & 3.76 & 4.62 \\
\hline
\end{tabular}

The photocatalytic efficiency observed varies greatly, depending on different factors, not only on the nature of photocatalytic product tested itself but also the substrate on which it is applied. Obviously, the higher the photocatalytic efficiency observed in the laboratory, the greater the estimated deposition velocity. It is, therefore, so that deposition rates estimated for all the tested products are also very different. Thus, the wide range of deposition rates calculated for photocatalytically active products, concrete pavement $(0.06-6.60)$ $\left(10^{-3} \mathrm{~m} \mathrm{~s}^{-1}\right)$, bituminous pavement $(0.30-4.64)\left(10^{-3} \mathrm{~m} \mathrm{~s}^{-1}\right)$ and facade $(0.42$ 3.89) $\left(10^{-3} \mathrm{~m} \mathrm{~s}^{-1}\right)$, is reflection of this fact. The essay $E 3_{\mathrm{ebm}}$ has been included here for comparative purposes and because the photocatalytic product tested is that which has been used for the experiment in ambient air described just below.

\section{Estimation of $\mathrm{NO}_{\mathrm{x}}$ deposition velocities from an experimental study at real ambient conditions}

Estimating the efficiency of $\mathrm{NO}_{\mathrm{x}}$ photocatalytic products on surfaces in outside environment presupposes establishing vertical gradients of the studied gas concentration in the atmosphere as a result of the sink effect induced by the photocatalytic surface and that such gradients are observable, that is, can be measured.

An experimental system has been designed, installed and put into operation based on a method that consists in measuring, in ambient air, vertical gradients of temperature and concentration of the gases to reach infer, subsequently, the flow of dry deposit of said gases using the theory of turbulent diffusion transport. To implement this method, the measurement site has been chosen to meet a set of stringent requirements in their boundary conditions. It has been located in an area, within the CIEMAT enclosure, sufficiently broad and reasonably far from obstacles that disrupt the flow of air and any emitting source of the studied gases that could be deposited and any others that may react with them. This system allows quantify the transport of $\mathrm{NO}$ and $\mathrm{NO}_{2}$ from the air to the photocatalytic 
surfaces and their potential removal as a result of the interaction of these gases with the active centres of $\mathrm{TiO}_{2}$ present in such surfaces.

The experimental device has also involved the preparation of a quasi-circular area of approximately $700 \mathrm{~m}^{2}$ covered by one of the photocatalytic products tested in the laboratory (code $\mathrm{E} 3_{\mathrm{ebm}}$ ), which is a real "photocatalytic island" in whose geometric centre is located the experimental assembly.

This consists of a mast that supports a set of meteorological sensors and probes installed at different heights on the same vertical for continuous sampling of environment air. With this measurement system, it can determine, above surface level, the vertical gradient of temperature $(27$ and $220 \mathrm{~cm})$, air humidity $(27 \mathrm{~cm})$, global solar radiation at the surface $(270 \mathrm{~cm})$ and speed and wind direction $(342 \mathrm{~cm})$.

Air samples continuously obtained at three different levels (16, 85 and 270 $\mathrm{cm}$ ) are transported by thermally-insulated Teflon tubing to a point outside the photocatalytic surface, away from its influence, where the control booth of the experiment is located. Additionally, it has placed a sampling air probe in an external reference point, off the island and at a sufficiently high level $(350 \mathrm{~cm})$, constituting the reference point for the $\mathrm{NO}_{\mathrm{x}}$ concentration level. Inside the booth, the $\mathrm{NO}_{\mathrm{x}}$ analyser, the suction system of the air sample lines, the system of sequential selection of the air sample to be analysed at each time and, also a computer program that implements the control functions of the whole experiment and data acquisition.

The numerical approach used to estimate the deposition velocity due to the photocatalytic surface is based on two assumptions:

1) That the site is sufficiently horizontally homogenous so that the MoninObukhov Similarity Theory (MOST) can be applied.

2) That the chemical reactions between the measurement points and the ground can be neglected (e. g. that NO can be considered passive for this case).

The first assumption has been considered valid because the boundary of the photocatalytic island is at more than $17_{\mathrm{Z}_{2 c}}$ from the measurement tower, with $\mathrm{Z}_{2 \mathrm{c}}$ height of the top concentration measurement. This fetch should be sufficient to ensure quasi-homogeneous conditions. The second assumption is considered valid based on that "close to the surface $(2 \mathrm{~m})$ there are small differences between the flux of the chemical species and the flux of the inert one (deviations of the order of $10 \%)$ " [10].

The combination of these two assumptions implies that the flux of $\mathrm{NO}_{\mathrm{x}}$ deposited at the surface, $F_{\text {surf }}=-c_{O} \cdot v_{P}$ (where $c_{O}$ is the gas-phase concentration close to the photocatalytic surface and $v_{P}$ is the "photocatalytic" surface deposition velocity) is equal to the downward flux of $\mathrm{NO}_{\mathrm{x}}$ at any height $z$ in the surface layer, which can be expressed, following MOST, as $F=-c_{*} u_{*}$ (where $u_{*}$, is the friction velocity, and $c_{*}=\frac{k\left(c(z)-c_{o}\right)}{0.74\left(\ln \left(\frac{z}{z_{o}}\right)-\psi_{H}\left(\frac{z}{L}\right)\right)}$, being $\psi_{H}\left(\frac{z}{L}\right)$ the stability function). 
From this, it can be easily derived an expression for $v_{P}$ as a function of the concentrations measured at two heights $(0.16 \mathrm{~m}$ and $0.85 \mathrm{~m}$ above ground level, a.g.l.), $c_{1}$ and $c_{2}$ :

$$
v_{P}=\frac{\left(c_{1}-c_{2}\right)}{\frac{c_{2}}{v_{D}\left(z_{1 c}\right)}-\frac{c_{1}}{v_{D}\left(z_{2 c}\right)}}
$$

Here $v_{D}$ is an aerodynamic deposition velocity defined as: $v_{D}\left(z_{C}\right)=$ $\frac{k u_{*}}{0.74\left(\ln \left(\frac{z_{C}}{z_{o}}\right)-\psi_{H}\left(\frac{z_{C}}{L}\right)\right)}$.

The values of $u_{*}$ and the Monin-Obukhov Length $L=\frac{\theta u_{*}}{k g \theta_{*}}(\theta$, potential temperature; $\theta_{*}$, scaling temperature; $g$, acceleration due to gravity and $k$, von Kármán's constant) are derived using an iterative process starting from the temperature measurements at two heights $(0.27 \mathrm{~m}$ and $2.20 \mathrm{~m}$ a.g.l.), the wind speed measured at $3.42 \mathrm{~m}$ a.g.l. and an estimated roughness length of $0.001 \mathrm{~m}$.

The system has been operating from 25th September, 2014 to 31st January, 2015. Nevertheless, not in all conditions macroscopic vertical gradients of $\mathrm{NO}_{x}$ could be observed. In this work, we present the results of one selected measuring period characterized by episodic conditions (wind speeds less than $1.5 \mathrm{~m} \mathrm{~s}^{-1}$, moderate to strong radiation, greater than $400 \mathrm{~W} \mathrm{~m}^{-2}$, and relative humidity lower than 63\%) that taken place from 27th to 30th October, 2014, in which gradients of concentration and temperature clear and sustained over time could be observed.

Before applying the eqn (8) to estimate the photocatalytic deposition velocities, a moving average with a time window of 5 minutes has been applied to the data to eliminate unwanted noise. The estimated deposition velocities for both $\mathrm{NO}$ and $\mathrm{NO}_{2}$ are listed in Table 6 .

Table 6: $\quad$ Results of estimated $\mathrm{NO}_{\mathrm{x}}$ deposition velocities from the ambient air experiments on the photocatalytic island (implemented with the product tested in the essay $\left.\mathrm{E}_{\mathrm{cbm}}\right)$.

\begin{tabular}{|c|c|c|c|c|c|}
\hline Date & $\begin{array}{c}\text { Hour } \\
(\mathrm{UTC})\end{array}$ & $\begin{array}{c}\text { Average } \\
c_{\mathrm{NO}}(\mathrm{ppb})\end{array}$ & $\begin{array}{c}\text { Average } \\
c_{\mathrm{NO}}(\mathrm{ppb})\end{array}$ & $\begin{array}{c}v_{P}(\mathrm{NO}) \\
\left(10^{-3} \mathrm{~m} \mathrm{~s}^{-1}\right)\end{array}$ & $\begin{array}{c}v_{P}\left(\mathrm{NO}_{2}\right) \\
\left(10^{-4} \mathrm{~m} \mathrm{~s}^{-1}\right)\end{array}$ \\
\hline $27 / 10 / 2014$ & $\begin{array}{c}10: 50- \\
13: 45\end{array}$ & $13.29 \pm 3.14$ & $21.26 \pm 0.63$ & $1.11 \pm 0.57$ & $4.12 \pm 4.02$ \\
\hline $28 / 10 / 2014$ & $\begin{array}{c}10: 28- \\
13: 55\end{array}$ & $6.85 \pm 0.68$ & $17.09 \pm 1.39$ & $2.71 \pm 3.17$ & $2.91 \pm 2.82$ \\
\hline $29 / 10 / 2014$ & $\begin{array}{c}11: 03- \\
14: 30\end{array}$ & $14.79 \pm 6.21$ & $25.31 \pm 5.52$ & $1.75 \pm 1.18$ & $2.69 \pm 3.35$ \\
\hline $30 / 10 / 2014$ & $\begin{array}{c}11: 40- \\
14: 21\end{array}$ & $8.75 \pm 1.38$ & $21.89 \pm 2.29$ & $2.58 \pm 4.50$ & $2.74 \pm 2.79$ \\
\hline
\end{tabular}

These results are derived from experimental data in ambient air, so that fluctuations in the registered concentrations and temperatures are logical and reflected in the associated standard deviation to the estimated average value of the deposition velocities. 
It has been assumed that, under the climatological and meteorological conditions of the experiment, the transport-limited deposition velocities are much greater (often several orders of magnitude) than deposition velocities because the transport resistance is negligible relative to surface resistance.

As can be seen, the values of the estimated deposition rates for $\mathrm{NO}_{2}$ are an order of magnitude lower than those for the NO. As can be seen, the values of the estimated deposition rates in real environment for $\mathrm{NO}$ are in the range of that obtained in laboratory (Table 5). Besides, the estimates for $\mathrm{NO}_{2}$ are an order of magnitude lower than those for the NO. In any case, as already noted, this deposition process and its macroscopic effect (vertical concentration gradient) over the photocatalytic island have been detected only under specific ambient conditions.

Additionally, this experimental system has been simulated on a Computational Fluid Dynamics model to carry out a comparison between simulation results and experimental measurements under ambient conditions. Due to the high resolution of the model, aerodynamic term of deposition velocity is solved. Hence, the deposition velocity is implemented using laboratory data since only surface resistance is taken into account. The NO concentration gradients obtained in the simulations are similar to experimental results.

Photostationary state mechanism was used to reproduce chemical reactions in the atmosphere. NO concentration gradients at different levels close to the ground are compared with experimental measurements at these levels for two different periods. For the first case, 12 UTC of 29th October, the experimental NO concentration gradient was $0.6412 \mathrm{ppb}$ and the value obtained by the model $0.6492 \mathrm{ppb}$. In the second case, 12.30 UTC of 29th October, the gradients computed by measurements and model were 0.8446 and $1.0424 \mathrm{ppb}$, respectively. Therefore, the differences in the first case were lower than $1 \%$ while in the second one around $20 \%$. Considering the experimental fluctuations of concentration data, we can conclude that the model results are in agreement with measurements.

\section{Conclusions}

The results of a comparative study over a variety of photocatalytic materials and products of the European market are shown. A method based on a bed flow photo-reactor has been used for this purpose and show a wide range of airpurification performance depending on the material or product itself and the substrate on which the product is applied. Additionally, an experimental system for measuring the macroscopic effect potentially induced by a photocatalytically active surface in ambient air has been implemented.

Several numerical approaches have been used to derive $\mathrm{NO}_{\mathrm{x}}$ deposition velocities from those experimental data, both laboratory tests as field experiments. Even when the magnitude order for the NO deposition velocity is the same, the values differ significantly and a further investigation on limitations of these methods and the kinetics and dynamics of the processes involved is needed. 
The laboratory method as it has been implemented here should not be applied to infer any $\mathrm{NO}_{2}$ deposition velocity. However, the estimates from the field experiment in ambient air give values one magnitude order lower than those for NO. The ambient conditions on which this experiment have been carried out are substantially different from those set in the laboratory and the $\mathrm{NO}_{\mathrm{x}}$ deposition velocities reflect the enormous influence and complex interrelation of the variables governing the processes involved making difficult a direct comparison so far.

NO surface deposition velocity estimated for a selected photocatalytic product, applied on a photocatalytic surface in ambient air, has been implemented in a CFD model. Numerical simulation results were in good agreement with experimental data.

\section{References}

[1] EU $\mathrm{CO}_{2}$ emission standards for passenger cars and light-commercial vehicles, International Council on clean transportation, January, 2014. Online www.theicct.org/eu-co2-standards-passenger-cars-and-lcvs

[2] Air quality clean air for Europe directive (2008/50/EC), European Parliament and Council of 21 May, 2008. Online eur-lex.europa.eu/legalcontent/EN/TXT/?uri=CELEX:32008L0050

[3] International standard ISO 22197-1:2007, Fine ceramics (advanced ceramics, advanced technical ceramics) - Test method for air-purification performance of semiconducting photocatalytic materials - Part 1: Removal of nitric oxide, ISO, Geneva, 2007.

[4] Finlayson-Pitts B.J., Wingen L.M., Sumner A.L., Syomin D. \&, Ramazan K.A., The heterogeneous hydrolysis of $\mathrm{NO}_{2}$ in laboratory systems and in outdoor and indoor atmospheres: an integrated mechanism, Physical Chemistry Chemical Physics, 6, pp. 223-242, 2003.

[5] Fujishima A. \&, Zhang X.T. Titanium dioxide photocatalysis: present situation and future approaches. Comptes Rendus Chimie, 9(5-6), pp. 750760, 2006.

[6] Chen J. \& Poon C.S., Photocatalytic construction and building materials: From fundamentals to applications, Building and Environment, 44(9), pp. 1899-1906, 2009.

[7] Lim T.H, Jeong S.M., Kim S.D. \& Gyenis J., Photocatalytic decomposition of $\mathrm{NO}$ by $\mathrm{TiO}_{2}$ particles, Journal of Photochemistry and Photobiology, 134(3), pp. 209-217, 2000.

[8] Dalton J.S., Janes P.A., Jones N.G., Nicholson J.A., Hallam K.R. \& Allen G.C., Photocatalytic oxidation of $\mathrm{NO}_{\mathrm{x}}$ gases using $\mathrm{TiO}_{2}$ : a surface spectroscopic approach. Environmental Protection, 120(2), pp. 415-422, 2002.

[9] Ifang S., Gallus M., Liedtke S., Kurtenbach R., Wiesen P., Kleffmann J., Standardization methods for testing photo-catalytic air remediation. Materials: Problems and solution, Atmospheric Environment, 91, pp. 154$161,2014$. 
740 Sustainable Development, Vol. 2

[10] Galmarini, S., Vila-Guerau de Arellano, J. \& Duyzer, J., Fluxes of chemically reactive species inferred from mean concentration measurements, Atmospheric Environment, 31(15), pp. 2371-2374, 1997. 